\title{
Bilateral Reinforced Arm Swing Versus Single Arm Restraining on Affected Single Limb Support Time in Stroke Patients
}

\author{
JASMINE M. MAHMOUD, M.Sc.*; EMAN S. FAYEZ, Ph.D.*; SANDRAA M. AHMED, M.D.* and \\ MAHMOUD Y. EL-ZANATY, Ph.D.** \\ The Department of Physical Therapy for Neuromuscular Disorders and its Surgery, Faculty of Physical Therapy*and \\ The Department of Neurology, Faculty of Medicine**, Cairo University
}

\begin{abstract}
Background: Stroke is one of the major leading causes of morbidity and mortality worldwide. Hemiparesis is one among the major impairments after stroke. It significantly affects gait performance. Patients use less affected side over the affected side. This differentiated the transverse rotation of trunk and pelvis. Some researchers found that arm sling has positive effects in enhancing gait patterns especially during gait training sessions in hemiparetic patients who have excessive motion of COG. Some studies suggested that powerful swing of upper extremities instead of natural movement is more helpful for improving weight shifting of the trunk, and gait kinematics. However, the upper limb swing function during walking has not yet been clarified, and still subject of debate.
\end{abstract}

Aim of Study: To compare between effect of bilateral reinforced arm swing versus single arm restraining on the affected single limb support time in chronic hemiparetic stroke patients to take it into our consideration during gait rehabilitation after stroke.

Patients and Methods: Thirty male patients with chronic stroke with an average age of $54.96 \pm 4.5$ years participated in this study. All patients performed overground 10-MWT without any assistive devices over a $15-\mathrm{m}$ walkway at self-selected speed in 3 different conditions: Normal arm swing, affected arm restraining using arm sling and bilateral reinforced arm swing randomly for 3 trails each to calculate average walking speed. The same speed calculated was set on the treadmill of Biodex Gait Trainer 2TM system in meter per second $(\mathrm{m} / \mathrm{sec}$.) subjects performed a 3-minute walk under each of the previous conditions randomly with time interval 20 minutes between tests for recording of average time on affected side during gait cycle.

Results: The mean difference in time on the affected side between normal and sling conditions was $-0.37 \%$. There was no significant difference in time on the affected side between

Correspondence to: Dr. Jasmine M. Mahmoud,

The Department of Physical Therapy for Neuromuscular Disorders and its Surgery, Faculty of Physical Therapy, Cairo University normal and sling arm condition $(p=1)$. The mean difference in time on the affected side between normal and powerful conditions was $-3.2 \%$. There was a significant increase in time on the affected side in powerful compared with normal arm swing condition $(p=0.04)$. The mean difference in time of the affected side between sling and powerful conditions was $-2.83 \%$. There was a significant increase in time on the affected side in powerful compared with sling arm condition $(p=0.1)$.

Conclusion: The results suggest that powerful arm swing significantly increased the percent of weight bearing on affected side in chronic hemiparetic stroke patients. Hence, it is recommended to motivate the patient to swing his arm powerfully as much as he can during gait training sessions.

Key Words: Stroke-Hemiplegia-Gait-Arm swing -Arm sling.

\section{Introduction}

STROKE is one of the major leading causes of morbidity and mortality worldwide [1]. Survivors are suffering from several neurological deficits as hemiparesis, cognitive deficits, communication disorders, or visuospatial disorders [2]. It also can cause difficulty in ADL [3].

Human locomotion involves the smooth advancement of COG with the least amount of mechanical and physiological energy expenditure. This natural movement requires interaction between lower limbs, trunk, and therefore the upper limbs [4].

Arm swing is considered a distinctive apparent characteristic of human walking. Our arms tend to swing out of phase with our legs. It has several positive effects as improving metabolic efficiency by generating a torque that opposes the contralateral swing leg [5], and enhancing balance, equilibrium, 
and postural control for smoothing the walking motion [6].

Hemiparesis is significantly affecting gait performance. Slow velocity, decreased cadence, prolonged swing duration on the paretic side, prolonged stance duration on the nonparetic side, and step length asymmetry are the most common spatiotemporal patterns of hemiparetic gait compared with healthy subjects [7]

It had reported that the active movement of affected upper extremities is limited in hemiparetic patients and trunk was not rotated effectively during gait [8]. Patients use less affected side over the affected side. This differentiated the transverse rotation of trunk and pelvis [9].

Some researchers found that arm sling has positive effects in enhancing gait patterns especially during gait training sessions in hemiparetic patients who have excessive motion of COG. It can increase walking speed, stance period of the paretic side, and reduces double support time of the paretic side [10].

Other studies suggested that powerful swing of upper extremities instead of natural movement is more helpful for improving weight shifting of the trunk, and gait velocity [11] because of the activation of latissimus dorsi muscle and gluteus maximus that are connected by the thoracolumbar fascia. This linkage can make it possible to transfer the force and enhance trunk rotation and reduce vertical displacement of the pelvis on the most affected side [12].

This study was designed to clarify if arm swing can improve gait kinematics to take it into our consideration during gait rehabilitation after stroke.

\section{Material and Methods}

The study was conducted on thirty male patients with chronic hemiparesis due to cerebral infarction or cerebral hemorrhage. The patients were diagnosed and referred from a neurologist. CT scan and/or MRI was used to confirm the diagnosis. The patients were selected from Outpatient Clinic of Faculty of Physical Therapy, Cairo University and from El-Kasr El-Ainy Hospital in the period from 24 June 2020 to 31 December 2020.

\section{Inclusion criteria for the patients were:}

1- Common age from 45 to 60 years old.

2- Duration of illness from 6 months to 2 years post stoke.
3- Patients with sufficient cognitive abilities that enables them to understand and follow instructions.

4- BMI $<30$.

5- Able to perform over a 10-meter walk independently on an even surface with no walking aid.

6- MAS for upper and lower limbs 1 and $1+$.

7- Brunnstrom stage of recovery for upper and lower limbs IV, V.

Patients were excluded from the study if they had:

1- Neurological diseases that affect gait other than unilateral stroke (e.g.: Multiple sclerosis, peripheral neuropathy .... etc.).

2- Musculoskeletal disorders affecting gait kinematics such as severe arthritis, knee surgery. .... etc.

3- Cardiovascular problems or medical contraindications to performing treadmill walking.

4- Shoulder subluxation.

5- Visual, auditory problems.

6- Cognitive impairment.

All the patients signed an informed consent form after receiving information on the study purpose, procedure, possible benefits and risks, privacy and use of data then the following assessment steps were applied: All the patients perform overground 10-MWT without any assistive devices over a 15-m walkway. 2,5 meters were provided prior to and following the timed portion to allow acceleration and deceleration to occur outside the timed region (10 meters) at self-selected speed in 3 different conditions: Normal arm swing, affected arm restraining with arm sling and bilateral reinforced arm swing randomly for 3 trails each to calculate average walking speed $(\mathrm{m} / \mathrm{s})$. The same speed calculated was set on the treadmill of Biodex Gait Trainer 2TM system in meter per second $(\mathrm{m} / \mathrm{sec}$.) The participants walked on the treadmill for three minutes to familiarize themselves with treadmill walking. Treadmill walking speed was adjusted if the participant feels that the speed was not the comfortable walking speed. Subjects performed a 3-minute walk under each of the previous conditions randomly with time interval 20 minutes between tests for recording of average time on affected side during gait cycle.

\section{Statistical methods:}

Descriptive statistics in form of mean, standard deviation, median, interquartile range and frequency 
was conducted for the subjects' characteristics. One-way MANOVA with repeated measures was conducted to compare the average time on affected lower limb between the normal arm swing, with arm sling and bilateral reinforced arm swing. Significant results were followed by Bonferroni correction test for pairwise comparison. The level of significance for all statistical tests was set at $p<0.05$. All statistical tests were performed through the Statistical Package for Social Studies (SPSS) version 22 for windows. (IBM SPSS, Chicago, IL, USA).

\section{Results}

\section{Participants characteristics:}

Thirty male subjects with chronic stroke participated in this study. 11 (37\%) subjects had the right side affected and $19(63 \%)$ subjects had the left side affected. $10(33 \%)$ subjects had grade I spasticity and $20(67 \%)$ subjects with grade I+ in upper limb while $15(50 \%)$ subjects had grade I and $15(50 \%)$ subjects had grade I+ for lower limb. Table (1) showed the participant characteristics of the study group.

Comparison of time on the affected side between normal, sling and powerful arm swing:

The mean difference in time on the affected side between normal and sling conditions was $-0.37 \%$. There was no significant difference in time on the affected side between normal and sling arm condition $(p=1)$. The mean difference in time on the affected side between normal and powerful conditions was $-3.2 \%$. There was a significant increase in time on the affected side in powerful compared with normal arm swing condition ( $p=$ $0.04)$. The mean difference in time of the affected side between sling and powerful conditions was $-2.83 \%$. There was a significant increase in time on the affected side in powerful compared with sling arm condition $(p=0.1)$.

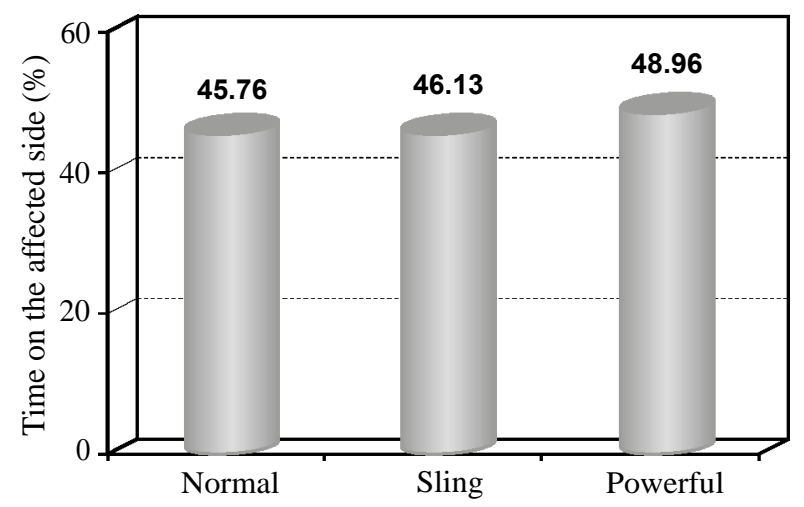

Fig. (1): Mean time on the affected side at normal, sling and powerful arm swing.
Table (1): Basic characteristics of participants.

\begin{tabular}{llcl}
\hline & Mean \pm SD & Minimum & Maximum \\
\hline - Age (years) & $54.96 \pm 4.5$ & 46 & 60 \\
- Weight $(\mathrm{kg})$ & $80.23 \pm 7.12$ & 70 & 90 \\
- Height $(\mathrm{cm})$ & $170.4 \pm 5.06$ & 160 & 179 \\
- BMI $\left(\mathrm{kg} / \mathrm{m}^{2}\right)$ & $27.61 \pm 1.54$ & 24.91 & 29.76 \\
- Duration of illness & $14.77 \pm 3.92$ & 8 & 22 \\
(months) & & & \\
\hline
\end{tabular}

SD: Standard Deviation.

Table (2): Comparison of time on the affected side between normal, sling and powerful arm swing.

\begin{tabular}{|c|c|c|c|c|c|}
\hline \multicolumn{3}{|c|}{$\begin{array}{l}\text { Time on the affected side }(\mathrm{m}) \\
\qquad \mathrm{X} \pm \mathrm{SD}\end{array}$} & \multirow{2}{*}{$\begin{array}{l}\text { F- } \\
\text { value }\end{array}$} & \multirow{2}{*}{$\begin{array}{c}p- \\
\text { value }\end{array}$} & \multirow[t]{2}{*}{ Sig. } \\
\hline Normal & Sling & Powerful & & & \\
\hline \multirow[t]{3}{*}{$45.76 \pm 6.73$} & $46.13 \pm 6.81$ & $48.96 \pm 5.79$ & 5.68 & 0.008 & S \\
\hline & & \multicolumn{4}{|c|}{$\begin{array}{l}\text { Multiple comparison } \\
\text { (Bonferroni test) }\end{array}$} \\
\hline & & MD & $p$-value & & Sig. \\
\hline \multirow{3}{*}{\multicolumn{2}{|c|}{$\begin{array}{l}\text { Normal vs. sling } \\
\text { Normal vs. powerful } \\
\text { Sling vs. powerful }\end{array}$}} & -0.37 & 1 & & NS \\
\hline & & -3.2 & 0.04 & & NS \\
\hline & & -2.83 & 0.01 & & $S$ \\
\hline $\begin{array}{l}\bar{x}: \text { Mean. } \\
\text { SD }: \text { Standarc } \\
\text { MD : Mean di }\end{array}$ & $\begin{array}{l}\text { Deviation. } \\
\text { fference. }\end{array}$ & $\begin{array}{l}p \text {-value } \\
\text { S } \\
\text { NS }\end{array}$ & $\begin{array}{l}\text { Probabili } \\
\text { Significa } \\
\text { Non Sign }\end{array}$ & $\begin{array}{l}\text { ity value. } \\
\text { nt. } \\
\text { hificant. }\end{array}$ & \\
\hline
\end{tabular}

\section{Discussion}

The present study was conducted to compare between effect of bilateral reinforced arm swing versus single arm restraining on average time on affected limb during gait cycle in chronic hemiparetic stroke patients to take it into our consideration during gait rehabilitation post stroke. Thirty male patients with chronic hemiparesis due to cerebral infarction or cerebral hemorrhage were participated in this study. The 10-MWT was used to measure self-selected spontaneous walking speed for the patients participated and average time on affected limb will be measured using the Biodex gait trainer 2 TM system.

The duration of illness was more than 6 months to make sure that the participants can walk independently without using assistive devices. $65 \%$ to $85 \%$ of stroke patients learn to walk independently after six months post stroke [13]

The result of current study revealed a significant increase in the average single support time on affected lower limb during walking with bilateral powerful arm swing in comparison with walking with normal arm swing or during walking with affected arm restriction using arm sling. This means 
that powerful arm swing is one of the methods that could be used to improve weight bearing on affected side in chronic hemiparetic stroke patients by increasing duration of its stance.

This result agreed with the results of Kim JS and Kwon $\mathrm{OH}[8]$ study, June-Seok M. and HyunJoo K. [14] study and Punt M. et al. [15] study. Kim JS and Kwon OH [8] reported that affected single support time, and non-affected single support time were significantly increased in emphasis arm swing when compared with both self-selected arm swing and constraint arm swing $(p<.05)$ in chronic hemiparetic stroke patients. June-Seok M. and HyunJoo K. [14] believed that the one-leg standing phase was increased by moving COG (Center of Gravity) forward when patients with stroke powerfully swing their upper extremities in intention. Punt M. et al. [15] confirmed that excessive arm swing significantly increases local dynamic stability of human gait in the Medio-Lateral direction. Increased sagittal plane arm movement out-of-phase with the ipsilateral leg reduces whole body angular momentum around the vertical axis. This implies that corrective torques around the hip of the stance leg could be lower when arm movement is more vigorous. Thus, reduced need to produce transverse plane torques around the hip of the stance leg might positively affect frontal plane balance as well given the anatomy of the hip musculature leading to increased time of single limb stance.

In this study, it was thought that increased single support time on affected side during powerful bilateral arm swing could be due to increased stability around hip and knee joints through increased firing of lower limb muscles by two different fascial connection. First, intended arm swing of affected side leading to significant increase of firing or activation of latissimus dorsi and gluteus maximus muscle which are connected through thoraco-lumbar fascia [12] leading to increased affected lower limb hip extension stability during stance. Second, powerful arm swing of non-affected side may increase firing of affected side knee extensors anatomically through spiral line of fascial connections to the rhomboids major and minor, the lower part of the serratus anterior, the external oblique, and the opposite of the internal oblique [16]leading to increased stability around knee during single limb stance on affected side.

This result contradicted with Cavan S. et al. [17]study. He reported that significant relationship between arm swing and walking ability in hemiplegic patients was not found in his study during different walking conditions. The discrepancy between the present and Cavan S. et al. [17] study may be due to smaller sample size, different degrees of spasticity and stages of recovery for the patients who represented the sample of his study.

The result of current study revealed that there was no significant difference in the percent of stance time on affected side during walking with single arm restriction using arm sling or waling with normal swinging of arms $p$-value $=1$. This result agreed with the results of Yavuzer G. and Ergin S. [18] study, Koo HM and Lee SY [19] study and Cavan S. et al. [17] study. The able-bodied persons in Yavuzer G. and Ergin S. [18] study did not show any differences in gait kinematic parameters between trials with and without arm sling. Koo HM and Lee SY [19] found that step time and single limb support did not show significant differences during walking with normal arm swing, dominant side constrained or non-dominant arm constrained using arm sling in young adults. Cavan S. et al. [17] reported that there is no significant difference in gait kinematics during walking with arm sling or with normal arm swing in hemiplegic patients. He also suggested the usefulness of using arm slings.

This indicates that there is no need to wear arm sling to control affected limb in order to increase dynamic gait stability or to enhance affected leg percent of weight bearing during gait cycle. Therefore, this study supported many other physical and occupational therapists who do not want hemiparetic patients to use walking aids such as canes or arm slings during daily life or during therapy sessions because they interfere with functional activities and enhance the flexor synergy of the upper extremity [20]

This result contradicted with Yavuzer G. and Ergin S. [18] and Fayez E. \& El-Wishy A. [10] Both confirmed that the percentage of stance phase on paretic side was increased with wearing arm sling aiming to support paretic side during walking leading to significant improving of gait pattern. The discrepancy between the present and their studies may be due to criteria of patients selected as duration from the onset of stroke, degree of spasticity and history of shoulder pain or subluxation. In this study chronic hemiparetic patients with mild spasticity were included. Patients were excluded if they have shoulder pain or subluxation.

\section{Conclusion:}

The results suggest that powerful arm swing significantly increased the percent of weight bearing on affected side in chronic hemiparetic patients. 
Hence, it is recommended to motivate the patient to swing his arm powerfully as much as he can during gait training sessions.

\section{References}

1- VIRANI S.S., ALONSO A., BENJAMIN E.J., BITTENCOURT M.S., CALLAWAY C.W., CARSON A.P., et al.: Heart Disease and Stroke Statistics-2020 Update: A Report From the American Heart Association. Circulation. 141 (9): e139-e596. Doi: 10.1161/CIR.0000000000000757, 2020.

2- SCHMID A., DUNCAN P., STUDENSKI S., LAI S., RICHARDS L., PERERA S., et al.: Improvements in Speed-Based Gait Classifications Are Meaningful. Stroke; a journal of cerebral circulation, 38: 2096-100. Doi: 10. 1 161/STROKEAHA. 106.475921, 2007.

3- BRUIJN S.M., MEYNS P., JONKERS I., KAAT D. and DUYSENS J.: Control of angular momentum during walking in children with cerebral palsy. Res. Dev. Disabil., Nov.-Dec., 32 (6): 2860-6. Doi: 10.1016/j.ridd.2011.05. 019, 2011.

4- MAGEE D.J.: Assessment of gait, In: Orthopaedic physical assessment. 6 th ed. St. Louis: Saunders. p. 981-1016, Orthopedic Physical Assessment-6 th Edition (elsevier. com), 2014.

5- MEYNS P., BRUIJN S. and DUYSENS J.: The how and why of arm swing during human walking. Gait Posture, 38: 555-62. https://doi.org/10.1016/j.gaitpost.2013.02.006, 2013.

6- WU Y., LI Y., LIU A.M., XIAO F., WANG Y.Z., HU F., et al.: Effect of active arm swing to local dynamic stability during walking. Human Movement Science, 45: 102-9. https://doi.org/10.1016/i.humov.2015.10.005, 2016.

7- PATTERSON K.K., GAGE W.H., BROOKS D., BLACK S.E. and MCILROY W.E.: Changes in Gait Symmetry and Velocity After Stroke: A Cross-Sectional Study From Weeks to Years After Stroke. Neurorehabilitation and Neural Repair, 24 (9): 783-90. https://doi.org/10.1177/ $1545968310372091,2010$.

8- KIM J.S. and KWON O.H.: The effect of arm swing on gait in post-stroke hemiparesis. Department of Physical Therapy, 7 (1): 95-101. Doi: 10.13066/kspm.2012.7.1.095, 2012.

9- VAN CRIEKINGE T., SAEYS W., HALLEMANS A., VELGHE S., VISKENS P.J., VEREECK L., et al.: Trunk biomechanics during hemiplegic gait after stroke: A systematic review. Gait \& Posture, 54: 133-43. https:// . doi.org/10.1016/i.gaitpost.2017.03.004, 2017.

10- FAYEZ E. and EL-WISHY A.: Impact of Arm Sling on Gait Pattern in Patients with Stroke: A randomized Cross- over Study, 16. Download citation of Impact of Arm Sling on Gait Pattern in Patients with Stroke: A randomized Cross-over Study (researchgate.net ), 2011.

11- LULIC' T.J., SUSIC' A. and KODVANJ J.: Effects of arm swing on mechanical parameters of human gait. Coll Antropol, 32 (3): 869-73. (PDF) Effects of arm swing on mechanical parameters of human gait (researchgate.net), 2008.

12- KIM T.Y.: The effect of changing gait speed and taking low arm weight on latissimus dorsi and gluteus medius and maximus muscle actiity. Department of Physical Therapy, Graduate school, Inje University, korea, https:// . doi.org/10.1589/ipts.25.1483, 2013.

13-ENG J. and TANG P.F.: Gait training strategies to optimize walking ability in people with stroke: A synthesis of the evidence. Expert review of neurotherapeutics, 7: 141736. Doi: 10.1586/14737175.7.10.1417, 2007.

14- JUNE-SEOK M. and HYUN-JOO K.: The Effect of Arm Swing Exercise on Gait and Balance in Stroke Patients. American Journal of Clinical and Experimental Medicine, 2 (6): 151-5. The Effect of Arm Swing Exercise on Gait and Balance in Stroke Patients: Science Publishing Group, 2014

15- PUNT M., BRUIJN S.M., WITTINK H. and VAN DIEËN J.H.: Effect of arm swing strategy on local dynamic stability of human gait. Gait \& Posture, 41 (2): 504-9. https://doi.org/10.1016/j.gaitpost.2014.12.002, 2015.

16- MYERS T.W.: Anatomy trains: myofascial meridians for manual and movement therapists. 3 rd ed. Edinburgh: Elsevier. 132-40. https://Anatomy Trains-3 rd Edition (elsevier.com), 2014

17- CAVAN S., TAKAMI A., MAKINO M. and IWATA M.: The Relationship between Arm Swing and Walking Abilities in Hemiplegia Patients. Hirosaki Medical Journal, 69 (1-4): 119-23. https:// doi.org/10.32216/ hirosakiigaku.69.1-4_119, 2019.

18- YAVUZER G. and ERGIN S.: Effect of an arm sling on gait pattern in patients with hemiplegia. Arch. Phys. Med. Rehabil., 83 (7): 960-3. https://doi.org/10.1053/ apmr.2002.33098, 2002.

19- KOO H.M. and LEE S.Y.: Gait analysis on the condition of arm swing in healthy young adults. Physical Therapy Rehabilitation Science, 5 (3): 149-54. Doi: 10.1371/ journal.pone.0136043, 2016.

20- FAGHRI P.D., RODGERS M.M., GLASER R.M., BORS J.G., HO C. and AKUTHOTA P.: The effects of functional electrical stimulation on shoulder subluxation, arm function recovery, and shoulder pain in hemiplegic stroke patients. Archives of Physical Medicine and Rehabilitation, 75 (1): 73-9. https://doi.org/10.1016/0003-9993(94)903417, 1994. 


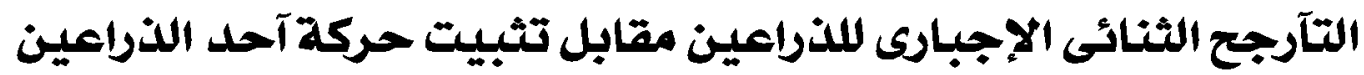

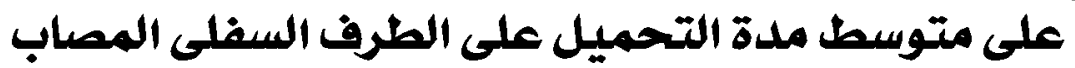 فى مرضى السكتة الدماغيلة الفرفية}

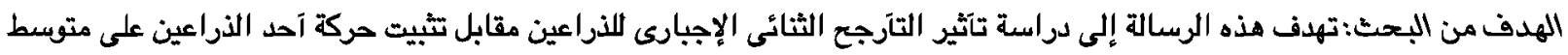
مدة التحميل على الطرف السفلى المصاب في مرضى السفى السكتة الدماغية.

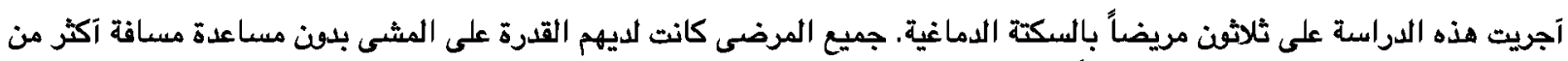

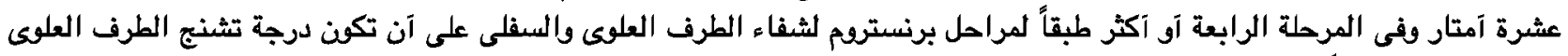

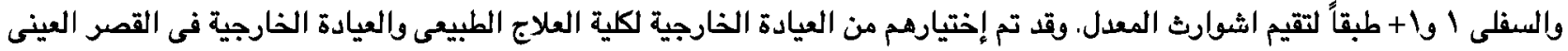

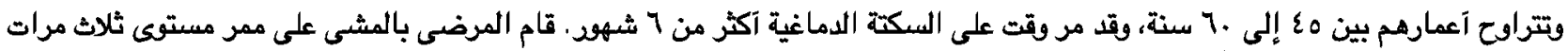

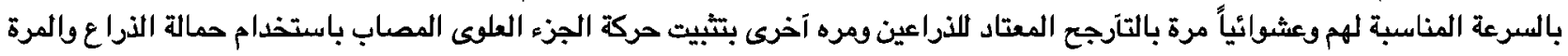

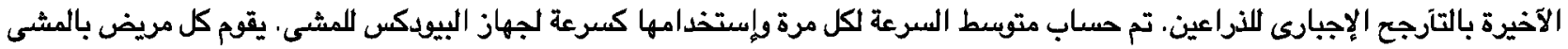

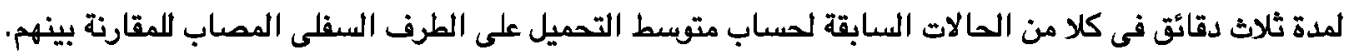

نتائج البعث: آظهرت النتائج وجود تحسن ذو دلالة إحصائية في تآثير التآرجع الثنائى الإجبارى اللذراعين على زيادة متوسط مدة التحميل على الطرف السفلى المصاب في مرضى البعى السكتة الدماغية.

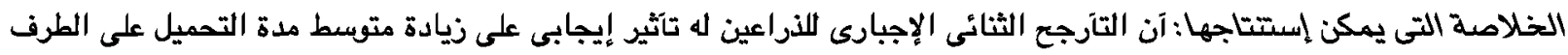

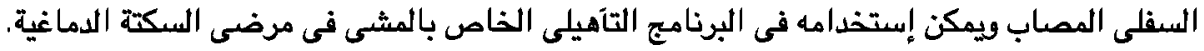

